\title{
ELABORATION PROCESS OF A MAP OF ACTIVITIES FOR STUDENTS IN DIFFERENT LEVELS IN THE COMPETENCE "INNOVATION, CREATIVITY AND ENTREPRENEURSHIP"
}

\author{
Andrés Boza1, Faustino Alarcón ${ }^{2}$, M.M.E. Alemany ${ }^{2}$, Llanos Cuenca ${ }^{1}$, Marta \\ Fernández-Diego', Mariluz Gordo', José Manuel Prats-Montalbán², Leonor \\ Ruiz $^{1}$ \\ ${ }^{1}$ Escuela Técnica Superior de Ingeniería Informática, Universitat Politècnica de València \\ (SPAIN) \\ ${ }^{2}$ Escuela Técnica Superior de Ingeniería Industrial, Universitat Politècnica de València
} (SPAIN)

\begin{abstract}
The paper focuses on offering each student the set of activities that best facilitate advancement in the competence of innovation, creativity and entrepreneurship. For this, it is essential to offer learning activities for the different levels that reinforce those aspects required for a convenient coverage of the competence.

The diversity of levels in the classroom for the competence led us to propose a map of appropriate activities for each level. The process of elaborating a map of activities for students in different levels in the competence "Innovation, creativity and entrepreneurship" includes a set of steps which has been described in the paper.
\end{abstract}

The process has achieved the established objectives by presenting a map of activities by levels.

Keywords: Innovation, Creativity, Entrepreneurship, Skill, Map of activities.

\section{INTRODUCTION}

The Universitat Politècnica de València (UPV) has defined a total of 13 transversal competences that must be incorporated into the training itineraries (curricula) of all students: CT1-Comprehension and Integration; CT2-Application of Practical Thinking; CT3-Analysis and Problem-Solving; CT4Innovation, Creativity and Entrepreneurship; CT5-Design and Project; CT6-Teamwork and Leadership; CT7-Ethical and Professional Responsibility; CT8-Effective Communication; CT-9-Critical Thinking; CT10-Awareness of Contemporary Problems; CT11-Lifelong Learning; CT12-Planning and Time Management; CT13-Specific Instrumentation [1]. This paper focuses on the transversal competence "Innovation, Creativity and Entrepreneurship".

The student's skills to innovate, be creative and be entrepreneur are, in most cases, unknown to the teacher when he/she begins his/her teaching activity with a new group of students. In general, the initial level of a student in non-transversal competences can be known by the structure of the previously studied curricula. However, for transversal competences, this starting level is not easy to identify. Furthermore, we found that there are more significant differences between students in the levels of transversal competences than in the levels of non-transversal competences.

The diversity of levels in the classroom for the competence led us to propose a map of appropriate activities for each level. So, the identification of a map of activities according to their level of difficulty can be used to propose different activities to our students depending of their levels (e. g. activities for beginners, intermediate and advanced level activities)[2] (Figure 1). 


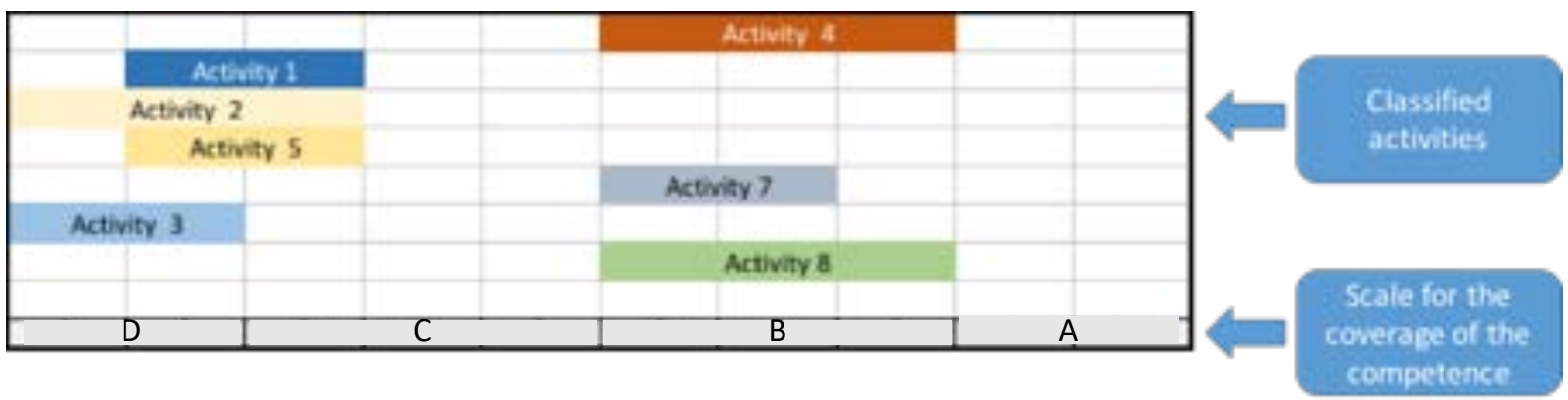

Figure 1: Map of classified learning activities for the customized development of transversal competences.

\section{OBJECTIVE}

The overall aim of this paper is to describe the process to build a map of learning activities where each activity will be adequate to cover a specific level of the competence "Innovation, creativity and entrepreneurship".

\section{METHODOLOGY}

The process of elaborating a map of activities for students in different levels in the competence "Innovation, creativity and entrepreneurship" includes the following steps:

1 Identification of activities.

The construction of the map requires the identification of learning activities oriented towards the acquisition of the transversal competence. This work is much simpler when the learning activities have already been conducted in the course and we already have a set of identified learning activities. However, if it is not the case, this process will be somewhat longer [2].

2 Definition of the levels.

The design of the scale is justified by the requirement to measure the level at which the learning activity contributes to the coverage of the competence. The data measuring instrument plays a central role in this process. Without it there are no classified observations. Thus, the measuring instrument records represent visible values of abstract concepts. In the case of transversal competences, the scale design is a complex process that depends on the approach of the teacher (as designer of the scale) concerning the analysis of the transversal competence and on the nature of the competence itself. For example, the transversal competence "Lifelong Learning" has very different dimensions from the competence "Effective Communication", both because of the intrinsic characteristics of the competences and because of the subjective concerns of the teacher when defining dimensions and indicators [3].

3 Classification of activities: Data collection.

Activities should be classified according to the scale established to construct the map of activities. That is, identifying the level (or levels) for each learning activity in order to place all activities on the map according to the defined scale. Thus, it is easy to identify the most suitable activities for each level of the scale.

We propose, for this step, to collect data among experts in the competence in order to know their classification of each learning activities in the previously defined scale.

4 Classification of activities: Analysis.

The data collected require an analysis process to assign activities at each level. We propose an interquartile analysis in order to link learning activities with levels. This type of analysis has been selected because it is very little affected by extreme values. The median value has been taken to obtain the value of the level. If a qualitative scale has been defined, it is necessary to quantify the values in order to use this kind of analysis. Finally, in this step, a debate among experts is required in case of a high interquartile range. 
5 Classification of activities: Map construction.

The numerical values of each activity must be transformed to the original scale in case of qualitative values. This information is used to build the activity map where each learning activity is linked to an (or more) levels in the scale.

6 Map analysis.

The location of the activities on the map allows: on the one hand, a) to identify sets of activities that work at the same level, so it may not be necessary to deploy a whole set of activities in the classroom, since with the completion of one of these activities the students would have already covered the level. And, on the other hand, b) to identify levels not covered by any activity.

\section{MAP OF ACTIVITIES FOR UPV STUDENTS IN THE COMPETENCE "INNOVATION, CREATIVITY AND ENTREPRENEURSHIP"}

The diversity of students levels in the classroom for the competence led us to propose a map of appropriate activities for each level. The process of elaborating a map of activities for students in different levels in the competence "Innovation, creativity and entrepreneurship" has included the previously defined steps:

1 Identification of activities.

In our case, 11 activities were identified as suitable to work in the "Innovation, Creativity and Entrepreneurship" competence. The selection process to identify these activities can be consulted in [4].

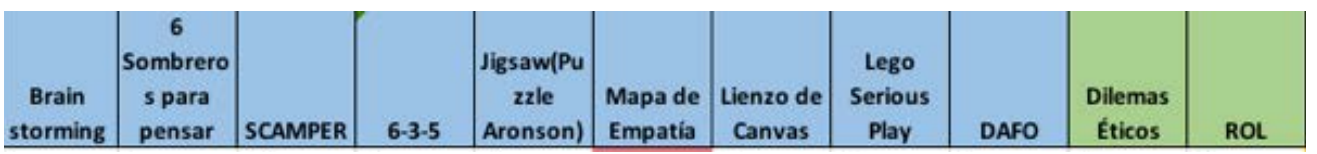

Figure 2: Learning activities for the transversal competence "Innovation, Creativity and Enterpreseurship".

2 Definition of the levels.

Four categories were defined to identify the different levels: D. Not achieved; C. Under development; B. Good; A. Excellent.

Furthermore, this scale was used for I. Undergraduate students ( $1^{\text {st }}$ and $2^{\text {nd }}$ year), II. Undergraduate students ( $3^{\text {rd }}$ and $4^{\text {th }}$ year), and III. Master students.

3 Classification of activities: Data collection.

Data from teachers who are experts in the competence were collected systematically to classify the activities. Thus, each teacher assigned each activity to one or two levels of the scale (from A to D), this for the 3 levels of studies (Level I: 1 st and 2 nd year, Level II: 3 rd and $4^{\text {th }}$ year, Level III: Master). A restriction was introduced: the level assigned to an activity (A, B, C or D) should be maintained or evolve to lower levels on the scale as we move from level I to level II and level III (due to student progression). This is justified by the fact that the student progresses with their level of studies and will also require a higher level of competence so the activity will be suitable for students of the same level or lower.

4 Classification of activities: Analysis.

The data collected require an analysis process to assign activities at each level. It is necessary to quantify (4 to 1 ) the qualitative scale (A to $D$ ) in order to perform an interquartile analysis. The 11 activities were analyzed for three study levels (I, II and III), so 33 results were obtained, and only in 6 cases was required a subsequent debate due to an elevated interquartile range.

Figure 3 shows the results of this analysis where each learning activity was linked to one or two levels in the scale (A to D) for each study level (I, II, III). A debate was required, for cells in red in the Figure, due to their elevated interquartile range. 


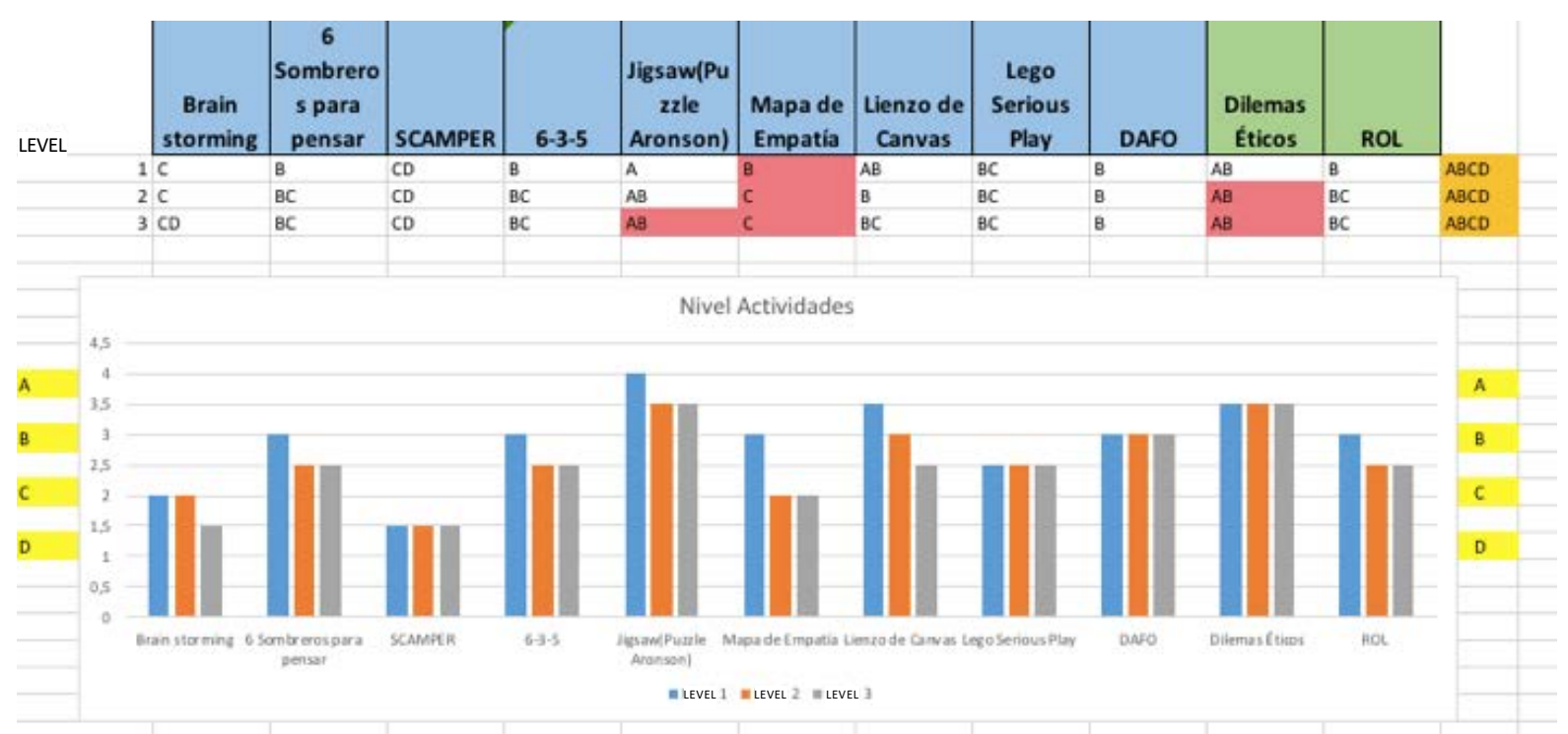

Figure 3: Analysis of the collected data to classify activities.

5 Classification of activities: Map construction.

The numerical values of each activity must be transformed to the original scale (A-D). This information was used to build three activity maps, one for each level of studies (I, II and III).

\begin{tabular}{l|l|l|l|l}
\hline LEVEL1 & \multicolumn{2}{|l|}{} \\
\hline Brain storming & A & B & C & D \\
\hline 6Sombreros para pensar & & & & \\
\hline SCAMPER & & & & \\
\hline 6-3-5 & & & & \\
\hline Jigsaw(Puzzle Aronson) & & & & \\
\hline Mapa de Empattia & & & & \\
\hline Lienzo deCanvas & & & & \\
\hline Lego Serious Play & & & & \\
\hline DAFO & & & & \\
\hline Dilemas Éticos & & & & \\
\hline ROL & & & & \\
\hline
\end{tabular}

\begin{tabular}{l|l|l|l|l}
\hline LEVELL2 & \multicolumn{5}{l|}{} \\
\hline Brain storming & A & B & C & D \\
\hline 6 Sombreros para pensar & & & & \\
\hline SCAMPER & & & & \\
\hline 6-3-5 & & & & \\
\hline Jigsaw(Puzzle Aronson) & & & & \\
\hline Mapa de Empatia & & & & \\
\hline Lienzo de Canvas & & & & \\
\hline Lego Serious Play & & & & \\
\hline DAFO & & & & \\
\hline Dilemas Éticos & & & & \\
\hline ROL & & & & \\
\hline
\end{tabular}

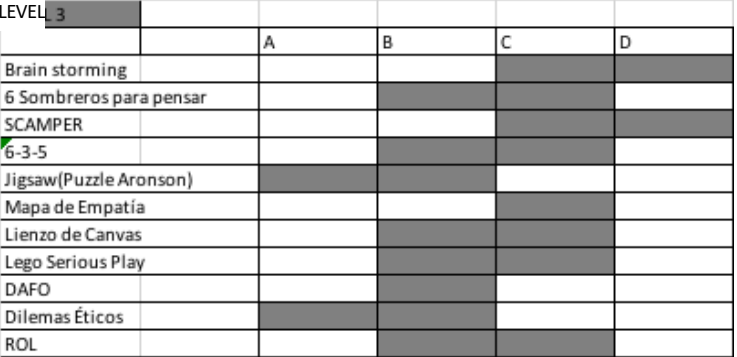

6 Map analysis.

The location of the activities on the map has allowed: on the one hand, a) to identify sets of activities that work at the same level, so it may not be necessary to deploy a whole set of activities in the classroom, since with the completion of one of these activities the students would have already covered the level. And, on the other hand, b) to identify that all levels are covered by, at least, one activity.

\section{CONCLUSIONS}

This paper presents the steps to be followed in designing the map of classified learning activities for the customized development of the transversal competence "Innovation, Creativity and Entrepreneurship".

The process has achieved the established objectives by presenting a map of activities by levels. The main line of proposing / identifying a set of activities according to different levels to define a map of 
activities of classified learning has been covered. The project has achieved the objectives set by presenting a map of activities by levels.

The paper is focused in the transversal competence "Innovation, Creativity and Entrepreneurship", however the proposed methodology has approached the problem from a general perspective in order to be transferable to other transversal competences.

Thus, as indicated above, on the one hand it will be necessary to adapt the work to the nature of the competence, and on the other hand measurement scales may be conditioned by the designer's approach regarding the competence. An example would be to use the map to identify activities according to their level of difficulty (our approach, e. g. activities for beginners, intermediate and advanced level activities), versus using the map to identify activities according to the contents addressed (e. g. for each of these categories: Innovation, Creativity and Entrepreneurship).

The design of the map of classified learning activities enables:

1 To have a broad vision of the activities carried out for the development of the competence.

2 To identify overlaps of activities at the same level, which raises the question of whether or not to eliminate any of the activities.

3 To identify levels not addressed by any activity, which encourages the development of activities that cover levels not reached by other activities.

4 To offer the students the map of activities as a tool for their training.

In this way, the map of activities becomes a tool for the students, where they can identify the activities by level and work to a greater extent on the most suitable ones according to their needs and potential.

\section{ACKNOWLEDGEMENTS}

This research has been carried out under the project of innovation and educational improvement (PIME 2017-18 Ref. A10) funded by Universitat Politècnica de València.

\section{REFERENCES}

[1] Universitat Politècnica de Valencia, "Competencias Transversales UPV." [Online]. Available: http://www.upv.es/contenidos/COMPTRAN/. [Accessed: 01-Jul-2017].

[2] A. Boza, M. Fenandez-Diego, M. Gordo, and L. Ruiz, "Designing a map of classified learning activities for the customised development of transversal competences," INTED2018 Proc., pp. 3018-3086, 2018.

[3] A. Boza, L. Cuenca, M. del M. E. Alemany, F. Alarcón, and J. M. Prats-Montalbán, "Early identification of the student's level in the transversal competence 'Creativity, Innovation and Entrepreneurship,"' INTED2018 Proc., pp. 3091-3096, 2018.

[4] L. Ruiz, M. Fernandez-Diego, M. Gordo, F. Alarcón, M. del M. E. Alemany, A. Boza, and L. Cuenca, "DAICE - Diseño de actividades para la Competencia de Innovación, Creatividad y Emprendimiento en grado y máster," in Memoria PIME 2015-2016, pp. 253-287. 